\title{
ACE Inhibition Lowers Angiotensin-II-Induced Monocyte Adhesion to HUVEC by Reduction of p65 Translocation and AT1 Expression
}

\author{
Oliver Soehnlein ${ }^{a, c}$ Alexander Schmeisser ${ }^{b}$ Iwona Cicha $^{a}$ \\ Christine Reiss $^{a}$ Holger Ulbrich ${ }^{c}$ Lennart Lindbom ${ }^{c}$ Werner G. Daniel ${ }^{a}$ \\ Christoph D. Garlichs ${ }^{a}$ \\ ${ }^{\mathrm{a}}$ Medical Clinic II, Friedrich Alexander University of Erlangen-Nuremberg, Erlangen, and ${ }^{\mathrm{b}}$ Medical Clinic III, \\ Technical University of Dresden, Germany; ${ }^{c}$ Department of Physiology and Pharmacology, Karolinska Institute, \\ Stockholm, Sweden
}

\section{Key Words}

Angiotensin II - ACE inhibitor - Inflammation •

Atherosclerosis $\cdot$ Angiotensin receptor

\begin{abstract}
Angiotensin-converting enzyme (ACE) inhibitors interfere with several key events of vascular inflammation resulting in impressive reductions in coronary vascular events. However, in human arteries ACE inhibitors block the production of angiotensin II (Angll) incompletely because of the involvement of alternative pathways in local Angll formation. Therefore, our study concentrated on the presumed modulation by ACE inhibition of local Angll-mediated inflammatory actions by a mechanism independent of blockage of Angll formation. We analyzed the effect of the ACE inhibitor ramiprilat on Anglldependent cell adhesion molecule (CAM) expression and adhesion of monocytic THP-1 cells to endothelial cells. Angll induced upregulation of P-selectin, VCAM-1 and ICAM-1 on endothelial cells via activation of AT1, which was correlated with enhanced THP-1 adhesion in flow chamber assays. Both enhanced adhesion and adhesion molecule expression were significantly reduced by pretreatment with ramiprilat. Ramiprilat reduced AT1 expression on endothelial cells and decreased the Angll-
\end{abstract}

induced p65 translocation into the nucleus. Diminished AT1 expression and adhesion molecule expression in response to ramiprilat treatment were partially reversed after incubation with a bradykinin 2 receptor antagonist, suggesting that elevated bradykinin levels under ACE inhibition may be involved in the beneficial effect of ACE inhibitors. Thus, modulation of the local Angll system by ramiprilat may at least in part contribute to the benefits of ACE inhibition in the treatment of atherosclerotic diseases.

Copyright (C) 2005 S. Karger AG, Basel

\section{Introduction}

Local inflammatory actions play a key role in the initiation and progression of atherosclerosis which will finally lead to clinical complications such as myocardial infarction and stroke [1, 2]. Angiotensin II (AngII), the main effector of the renin-angiotensin system (RAS), is known to be involved in various proinflammatory actions in the vascular wall, including adhesion molecule, chemokine and cytokine expression, and generation of reactive oxygen species [3]. Nuclear factor NF-кB is considered to be an important link between AngII and its inflammatory actions. Binding of AngII to the AngII receptor 1

\section{KARGER \\ Fax +4161306 1234 E-Mail karger@karger.ch} www.karger.com
C 2005 S. Karger AG, Basel $1018-1172 / 05 / 0425-0399 \$ 22.00 / 0$

Accessible online at: www.karger.com/jvr
Oliver Soehnlein

Medical Clinic II, University of Erlangen-Nuremberg

Ulmenweg 18

DE-91054 Erlangen (Germany)

Tel. +49 9131853 5896, Fax +49 9131853 2079, E-Mail Oliver.Sohnlein@fyfa.ki.se 
(AT1) results in activation of four different signaling pathways, of which at least three are known to activate NF-кB: activation of NADH/NADPH oxidase, activation of tyrosine kinase, and Gq uncoupling [4]. After activation, the NF- $\mathrm{kB}$ heterodimer consisting of $\mathrm{p} 50$ and p65 translocates from the cytoplasm into the nucleus where it binds target genes and stimulates transcription of specific sets of genes relevant to the pathophysiology of the vessel wall [5]. The AngII-mediated stimulation of NF- $\kappa$ B via AT1 leads to upregulation of proinflammatory cytokines, chemokines and adhesion molecules $[3$, 6].

Dzau [7] has documented the existence of both a local and a systemic RAS. While short-term effects of cardiovascular homeostasis such as vasoconstriction and hypertension can be ascribed to the systemic RAS, long-term effects such as inflammatory actions in the vascular wall relate to functions of the local RAS. Angiotensin-converting-enzyme (ACE)-like enzymes such as cathepsin G, cathepsin $\mathrm{D}$, tonin and chymase were identified locally in the vessel wall [3]. In particular, chymase plays an important role in local AngII formation in the atherosclerotic plaque. In the human aorta, $80-90 \%$ of the AngII-forming activity is chymase-dependent [8]. Chymase is mainly mast cell derived [9], while cathepsin $\mathrm{G}$ is expressed in neutrophils and monocytes [10]. The local accumulation of high levels of AngII, produced by ACE and alternative pathways of AngII production, activates AngII receptors on different cell types, leading to progressive lesion formation via proliferation of smooth muscle cells, formation of foam cells, and facilitation of thrombosis.

Previous studies have revealed that not all the potential anti-atherosclerotic actions of ACE inhibitors are shared by AT1 antagonists. Therefore, we suspected that additional mechanisms independent of the inhibition of AngII generation might be involved in the anti-atherosclerotic actions of ACE inhibitors. Results by Berkenboom et al. [11] showed that ramipril but not losartan could prevent ox-LDL-induced endothelial damage in Watanabe hypercholesterolemic rabbits. In hypercholesterolemic rabbits ACE inhibitors were found to be more effective than losartan in improving vascular function [12].

We therefore hypothesized that ACE inhibitors, in spite of the incomplete inhibition of tissue AngII formation, can modulate the local vascular AngII-mediated inflammatory action by influencing the inflammatory signal cascade in AT1-bearing cells of the atherosclerotic plaque. To this end, effects of the ACE inhibitor ramiprilat on the expression of endothelial cell adhesion molecules and on the adhesion of THP-1 cells to AngII-stimulated human umbilical vein endothelial cells (HUVEC) were analyzed.

\section{Materials and Methods}

\section{Cell Culture}

Monocytic THP-1 cells were cultured in RPMI-1640 (Biochrom, Germany) containing 10\% FCS (Biochrom) at a density of up to $1 \times 10^{6}$ cells $/ \mathrm{ml}$. HUVEC were isolated and cultured as described previously [13]. Endothelial cells were growth factor starved $24 \mathrm{~h}$ prior to stimulation with AngII. Ramiprilat, a gift from Aventis (Frankfurt, Germany), was dissolved at $1 \mathrm{~m} M$ in PBS and stored at $-20^{\circ} \mathrm{C}$ until use. Losartan, PD123.319, AngII, HOE-140, des$\mathrm{Arg}^{9},\left[\mathrm{Leu}^{8}\right]$-bradykinin, captopril, and lipopolysaccharide (LPS) were purchased from Sigma (Munich, Germany). Simvastatin was a kind gift from Merck (Darmstadt, Germany).

\section{Flow Cytometry}

After stimulation of HUVEC with AngII $(1 \mu M, 6 \mathrm{~h})$ and when indicated with ramiprilat $(1 \mu M, 20 \mathrm{~h}$ prior to AngII), losartan (1 $\mu M, 30$ min prior to AngII) or PD123.319 (1 $\mu M, 30$ min prior to AngII) cells were detached with accutase, washed with PBS and then incubated with $0.5 \%$ BSA in PBS for $30 \mathrm{~min}$ at $4^{\circ} \mathrm{C}$. HUVEC were stained with the respective antibody for $30 \mathrm{~min}$ at $4^{\circ} \mathrm{C}$. Antihuman CD106 PE(CBL 206P), anti-human CD62E PE(CBL180P) (Cymbus, UK), anti-human CD62P FITC, anti-human CD54 PE, mouse IgG1 PE isotype, mouse IgG1 FITC isotype (BD Biosciences, USA) were used. After two washes in PBS, cells were immediately assayed in Becton Dickinson FACS Calibur (Becton Dickinson, USA). Results are expressed as mean fluorescence intensity (MFI).

For analysis of angiotensin II receptor expression on HUVEC, cells were washed twice with PBS after treatment as indicated, incubated with $0.5 \%$ BSA in PBS for $30 \mathrm{~min}$ at $4^{\circ} \mathrm{C} .1 \mu \mathrm{g} / \mathrm{ml}$ of either anti human AT1 (306, SantaCruz), anti human AT2 (H-143, SantaCruz) or rabbit IgG (Sigma) was added for $30 \mathrm{~min}$ at $4^{\circ} \mathrm{C}$. After washing, cells were incubated with mouse anti-rabbit-FITC conjugated antibody (Sigma), washed again and assayed in Becton Dickinson FACS Calibur (Becton Dickinson).

\section{Flow Chamber Analysis}

Laminar flow chamber assays were performed on confluent HUVEC. Confluent endothelial cells were treated with AngII, ramiprilat, PD123.319 or losartan as described above. LPS at a concentration of $1 \mu \mathrm{g} / \mathrm{ml}$ for $4 \mathrm{~h}$ was used as positive control. HUVEC were washed twice with PBS before cell injection to wash off excessive reagents. Flow chamber experiments were performed with THP- 1 cells $\left(10^{6}\right.$ cells $\left./ \mathrm{ml}\right)$ resuspended in medium containing $1 \% \mathrm{FCS}$ and infused at $2 \mathrm{dyne} / \mathrm{cm}^{2}$ for $4 \mathrm{~min}$. The experiments were recorded with a CCD camera (Nikon DXM 1200, Düsseldorf, Germany) for off-line analysis. The analysis was performed by counting the number of adherent cells in four separate fields in each well.

\section{Western Blotting}

After treatment of HUVEC with ramiprilat or simvastatin, cells were washed with PBS and lysed with $0.1 \mathrm{ml} / 10^{6}$ cells of lysis buffer (50 m $M$ HEPES, $150 \mathrm{~m} M \mathrm{NaCl}, 1 \%$ Triton X-100, $1 \mathrm{~m} M$ EDTA, 
Fig. 1. AngII enhances the expression of ICAM-1 (a), VCAM-1 (b), P-selectin (c) but not E-selectin (d) on HUVEC. HUVEC were stimulated with AngII (1 $\mu M, 6 \mathrm{~h})$ and when indicated with losartan $(1 \mu M)$ or PD123.319 $(1 \mu M)$. Values are given as MFI (mean \pm SD) in percent of basal expression, which was set to $100 \%$ in each experiment. $\mathrm{n}=7, * \mathrm{p}<0.05, * * \mathrm{p}<0.01$; n.s. $=$ not significant.

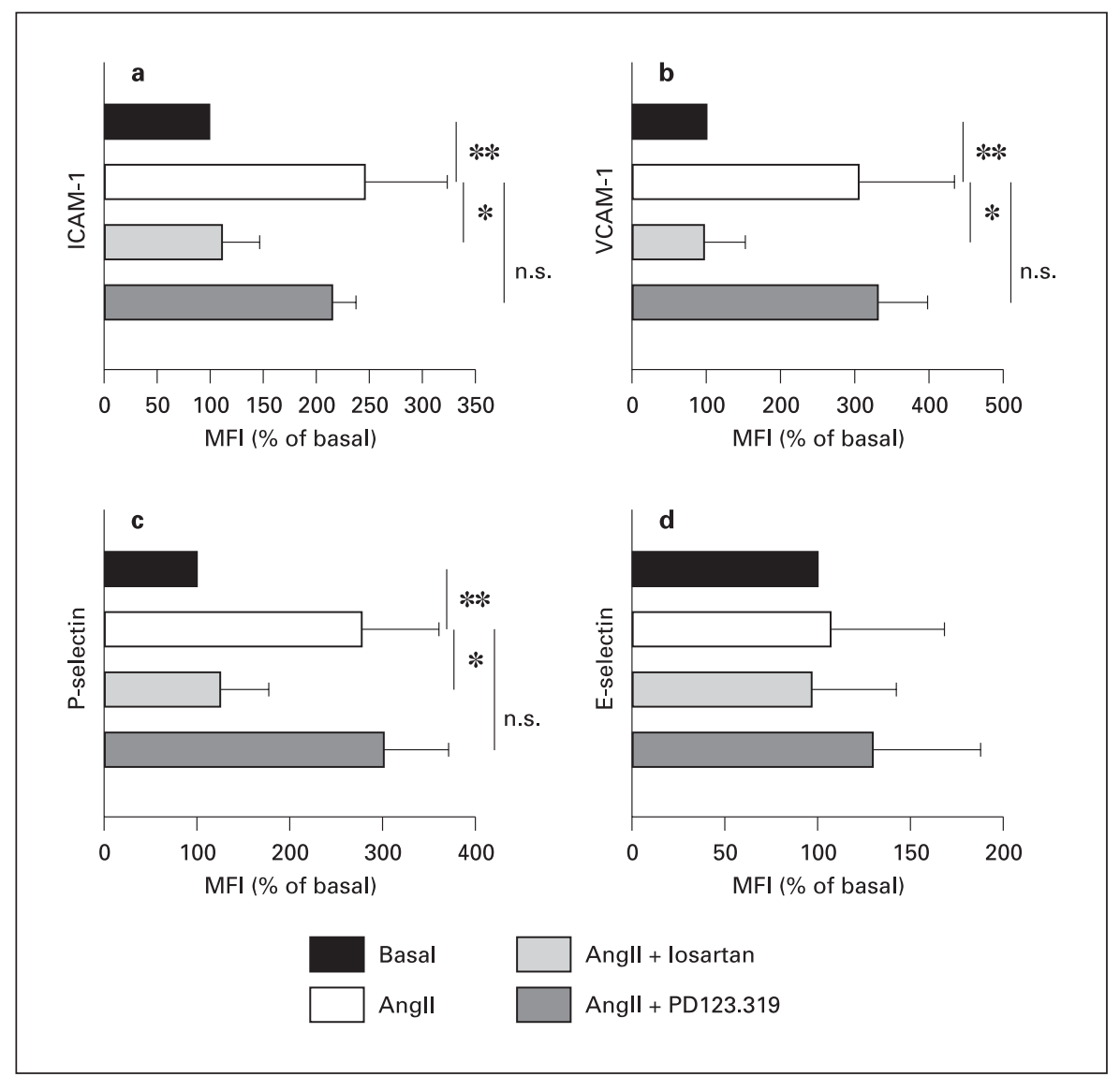

10\% glycerol, $1 \mathrm{~m} M$ PMSF, $1.9 \mathrm{mg} / \mathrm{ml}$ aprotinin, $0.5 \mathrm{mg} / \mathrm{ml}$ leupeptin, $\mathrm{pH}$ 7.4). Following a protein concentration assay, the proteins ( $30 \mu \mathrm{g}$ per lane) were separated by $10 \%$ SDS-PAGE under reducing conditions and transferred to a PVDF membrane. Nonspecific binding was blocked by $10 \%$ dry milk in TBS-Tween (10 $\mathrm{m} M$ Tris, $100 \mathrm{~m} M \mathrm{NaCl}, 0.1 \%$ Tween-20, $\mathrm{pH}$ 7.5) overnight at $4^{\circ} \mathrm{C}$. Incubation with anti-AT1 (1:500, Santa Cruz, Germany, clone 306) or anti-AT2 antibody (1:500, Santa Cruz, clone H-143) was followed by incubation with horseradish peroxidase-conjugated goat anti-mouse antibody (1:5,000, Amersham, UK). Staining was visualized by an enhanced chemiluminescence system (Amersham). To confirm equal protein loading, membranes were stained with Ponceau S. The relative amount of AngII receptor expression was estimated using densitometric analysis (Quantity One, BioRad, Germany).

\section{p65 Translocation Assay}

The assay was performed as described previously [14]. Briefly, after stimulation HUVEC were harvested and washed with PBS. Nucleus preparations were obtained by incubating the cells with $200 \mu$ l Pipes-Triton buffer (10 m $M$ Pipes, $0.1 \mathrm{M} \mathrm{NaCl}, 2 \mathrm{~m} M$ $\mathrm{MgCl}_{2}$ and $0.1 \%$ Triton $\mathrm{X}-100$ in $\mathrm{H}_{2} \mathrm{O}$ ) for $30 \mathrm{~min}$ at $4^{\circ} \mathrm{C}$. Thereafter nuclei were stained with mouse anti-human NF-кB p65 monoclonal antibody (Santa Cruz, clone F-6) or with the matching isotype (DakoCytomation, Germany, X0931) at $5 \mu \mathrm{g} / \mathrm{ml}$ for $30 \mathrm{~min}$.
After washing, the nuclei were incubated with a secondary FITCconjugated goat anti-mouse antibody (DakoCytomation, F0479) for an additional $30 \mathrm{~min}$ at $4^{\circ} \mathrm{C}$. The nuclei were then counterstained with propidium iodide (PI, BD Biosciences) at $1 \mu \mathrm{g} / \mathrm{ml}$ and immediately analyzed using FACS.

\section{Statistics}

Data are presented as mean \pm SD and were analyzed by analysis of variance (ANOVA). When significant main effects were observed, a Tukey post hoc test for multiple comparisons was performed. The level of significance set for the investigation was $p<0.05$.

\section{Results}

\section{AngII Induces Monocyte Adhesion to HUVEC via AT1-Mediated Adhesion Molecule Expression}

Adhesion molecule expression on HUVEC was analyzed by FACS upon stimulation with AngII $(1 \mu M)$ for $6 \mathrm{~h}$. In comparison with unstimulated cells, we found a clear-cut increased expression of ICAM-1 ( $p<0.01$, fig. 1a), VCAM-1 ( $p<0.05$, fig. 1b) and P-selectin ( $p<0.05$, 


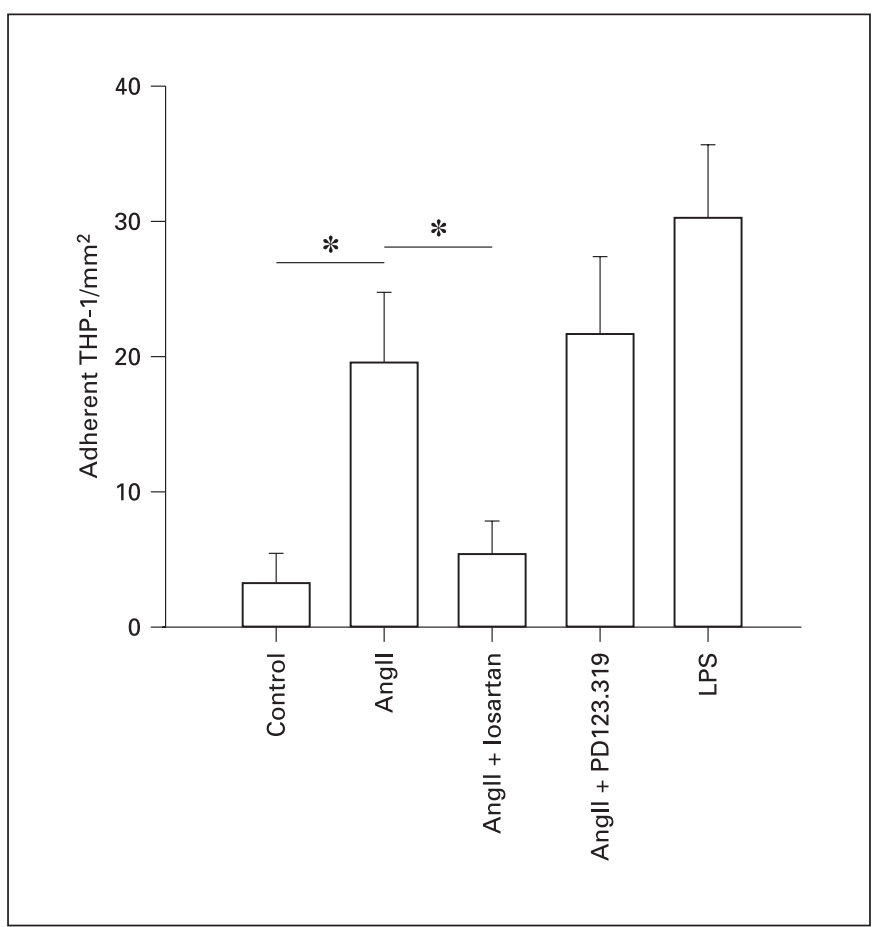

Fig. 2. Effect of AngII on THP-1 adhesion to HUVEC. THP-1 cells were perfused over AngII-treated $(1 \mu M, 6 \mathrm{~h})$ HUVEC monolayers for $4 \mathrm{~min}$ and the number of adherent cells in four different fields was subsequently counted. Losartan $(1 \mu M)$ and PD123.319 $(1 \mu M)$ were added $30 \mathrm{~min}$ before AngII stimulation. Adhesion of THP-1 cells to HUVEC under different conditions is expressed as adherent cells $/ \mathrm{mm}^{2}$. Results are given as mean $\pm \mathrm{SD},{ }^{*} \mathrm{p}<0.01, \mathrm{n}=6$.

fig. 1c) but not E-selectin ( $p=0.7$, fig. 1d). Enhanced expression of adhesion molecules upon AngII stimulation was blocked by pretreatment with the AT1 antagonist losartan but not the AT2 antagonist PD123.319, indicating an AT1-dependent mechanism to be responsible for the induction. The stimulation over $6 \mathrm{~h}$ was found to be more effective than treatment for 4 or $24 \mathrm{~h}$ (data not shown). However, significant induction of E-selectin could not be detected at any time, although stimulation with LPS $(1 \mu M, 4 \mathrm{~h})$ resulted in a markedly increased expression of this molecule (data not shown).

To demonstrate a functional correlate to the enhanced adhesion molecule expression, flow chamber assays were performed. THP- 1 cells were perfused at 2 dyne $/ \mathrm{cm}^{2}$ over stimulated HUVEC and the number of adherent cells was analyzed in four different fields. Treatment of HUVEC with AngII resulted in a significant enhancement of THP-1 adhesion ( $p<0.001$, fig. 2 ) which was almost completely blocked by losartan. PD123.319 did not signifi- cantly alter the adhesion compared to AngII-treated cells.

\section{Ramiprilat Reduces AngII-Induced Expression of Adhesion Molecules and Adhesion of Monocytes}

We further investigated the effect of the ACE inhibitor ramiprilat in our study. In HUVEC not stimulated with AngII, the adhesion molecule expression was not significantly influenced by ramiprilat (data not shown). In contrast, in AngII-stimulated HUVEC $(1 \mu M, 6 \mathrm{~h})$, pretreatment with ramiprilat $(1 \mu M, 20 \mathrm{~h})$ caused a significant reduction in adhesion molecule expression as compared with cells stimulated with AngII only (fig. 3a). Similarly, HUVEC treated with LPS $(1 \mu \mathrm{g} / \mathrm{ml}, 4 \mathrm{~h})$ resulted in increased ICAM-1 expression, which was significantly attenuated by $45 \%$ after pretreatment with ramiprilat (1 $\mu M, 20 \mathrm{~h})$ (data not shown).

Since enhanced adhesion molecule expression is associated with increased THP-1 adhesion to endothelium, we analyzed if ramiprilat-induced decrease in adhesion molecule expression also resulted in reduced monocyte adhesion. Therefore, HUVEC were treated with ramiprilat $(1 \mu M)$ for $20 \mathrm{~h}$ prior to stimulation with AngII. The ACE inhibitor caused a significant reduction in THP-1 adhesion to endothelial cells ( $p<0.01$, fig. $3 b$ ).

\section{Ramiprilat Reduces AngII-Mediated p65 \\ Translocation in HUVEC}

As ramiprilat was effective despite AngII stimulation, the ACE inhibitor had to interact with the RAS distal from AngII formation. We therefore analyzed the p65 translocation and the AT1 expression on HUVEC as possible mechanisms responsible for the reduced THP-1 adhesion. AngII-dependent increase in adhesion molecule expression can be mediated intracellularly by increased activity of NF-kB, which results in enhanced p65 translocation into the nucleus. Before the measurement of $\mathrm{p} 65$ translocation, HUVEC were stimulated with $1 \mu M$ AngII for $3 \mathrm{~h}$, which was the optimal experimental time in this study. Nuclei were then extracted and stained for p65. Staining of p65 in the nuclei of unstimulated HUVEC did not differ significantly from isotype control, indicating a low basal activity of the cells. Basal values were not altered by incubation with ramiprilat. In our assays, AngII significantly increased p65 translocation compared to untreated control (fig. 4a, b, p < 0.01). p65 translocation after AngII treatment reached $74 \pm 10 \%$ of LPS $(1 \mu \mathrm{g} / \mathrm{ml})$ stimulation. The AngII-mediated p65 translocation was blocked with losartan, and therefore clearly AT1-mediated. Pretreatment with ramiprilat $(1 \mu M)$ for $20 \mathrm{~h}$ caused 
Fig. 3. AngII-induced adhesion molecule expression (a) and adhesion of THP-1 to HUVEC (b) is reduced by ramiprilat pretreatment. a HUVEC were treated with ramiprilat $(1 \mu M) 20 \mathrm{~h}$ prior to AngII stimulation. Basal and stimulated MFI varied among P-selectin, VCAM-1, and ICAM-1. To allow comparisons between P-selectin, VCAM-1, and ICAM-1 levels, basal expression was set as 100\% (dashed line). Bars represent expression of P-selectin, ICAM-1 and VCAM-1 expressed as percentage of basal. $* \mathrm{p}<0.05,{ }^{*} * \mathrm{p}<0.01$ compared to respective basal control, ${ }^{\circ} \mathrm{p}<0.05,{ }^{\circ} \mathrm{p}<0.01$ compared to respective AngII stimulation, $\mathrm{n}=6$, results are given as mean \pm SD. b Flow chamber assays were performed as described in the Methods section. Before AngII stimulation HUVEC were treated with ramiprilat $(1 \mu M)$. Results are given as mean $\pm \mathrm{SD}, * \mathrm{p}<0.01, \mathrm{n}=6$.

Fig. 4. Ramiprilat treatment significantly reduces AngII-induced p65 translocation into the nucleus. HUVEC were stimulated with AngII $(1 \mu M)$ for $3 \mathrm{~h}$ and when indicated pretreated with losartan $(1 \mu M)$ or ramiprilat $(1 \mu M)$. Nuclear extracts were stained for p65 and analyzed using FACS. a Representative histogram overlay showing basal (light gray), AngII-stimulated (black) and ramiprilat-pretreated (dark gray) p65 staining in the nucleus. b Ordinate gives the isotype-corrected MFI for various treatments. $* \mathrm{p}<0.01, \mathrm{n}=6$, values are given as mean $\pm \mathrm{SD}$.
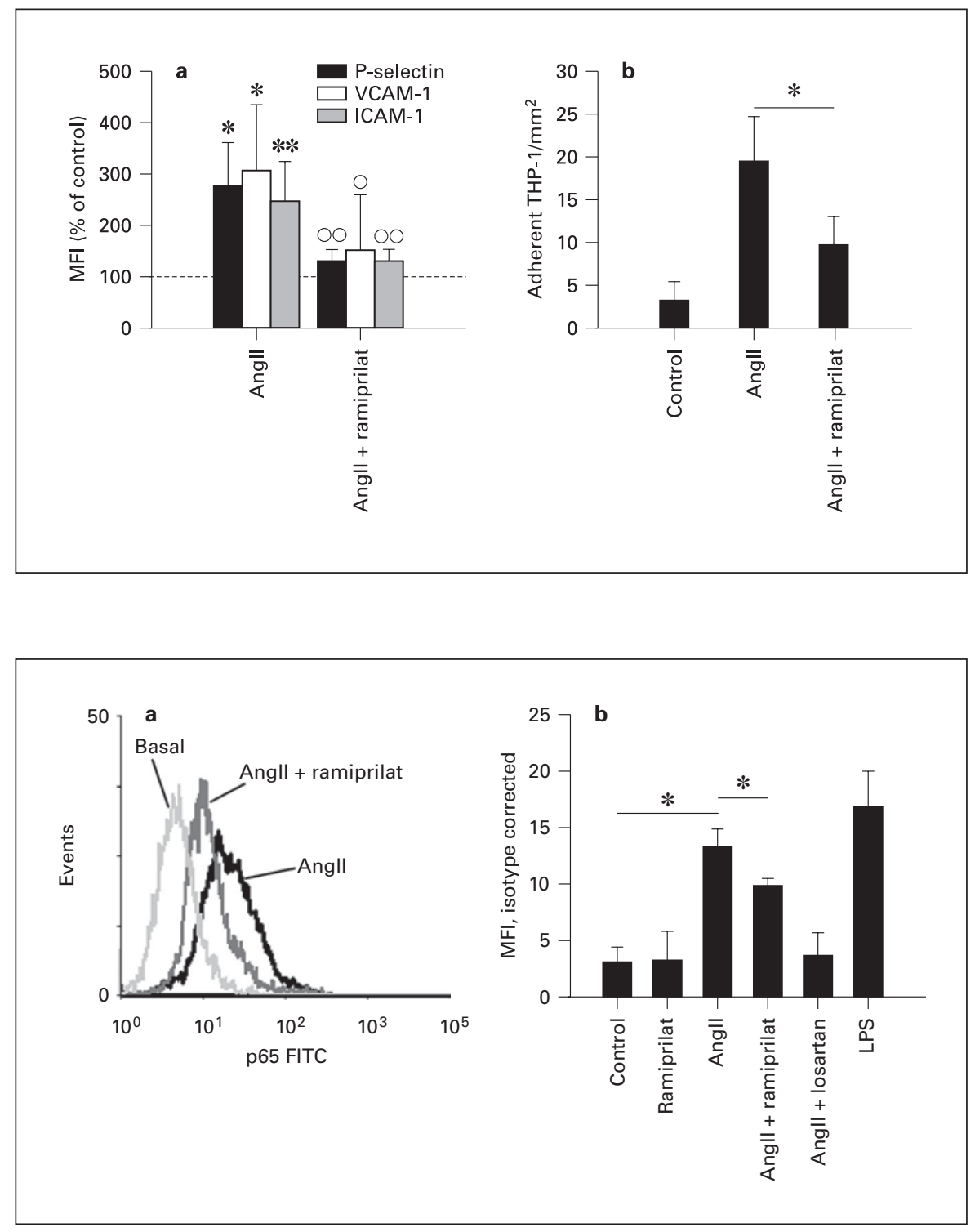

a significant reduction in p65 translocation (fig. 4b). To exclude contamination of nuclear fractions with cytoplasm we stained the nuclear extracts with anti-CD54 PE after HUVEC were stimulated with $1 \mu M$ LPS for $2 \mathrm{~h}$. No difference between the isotype and the basal or stimulated CD54 expression could be detected (data not shown).

\section{Ramiprilat Downregulates AT1 Expression on HUVEC}

Next, we tested the effect of ramiprilat on the expression of AT1 and AT2 receptors. Western blot analyses of whole cell lysates of HUVEC treated for $24 \mathrm{~h}$ with ramiprilat in different concentrations ( 1 and $10 \mu M$ ) were performed (fig. 5a). Ramiprilat markedly reduced AT1 expression, while AT2 levels remained stable. As statins are known to reduce AT1 expression [15], we used simvastatin as a positive control in our experiment. Treatment of HUVEC with 1 and $10 \mu M$ simvastatin reduced AT1 expression to a greater extent than ramiprilat. The expression of AT2 was not significantly affected (fig. 5b).

In FACS analysis we could further elucidate that downregulation of AT1 by ramiprilat is both time- (fig. 
Fig. 5. Effect of ramiprilat, captopril and simvastatin on expression of AT1 and AT2 in HUVEC. a, b Figures show representative Western blots of whole-cell lysate for three independent experiments. In each subfigure the densitometric analysis of the band intensities is given below. $\mathrm{n}=3$, $* \mathrm{p}<0.01$, values are expressed in percent of basal expression as mean $\pm \mathrm{SD}$. a AT1/ AT2 expression in HUVEC after treatment with 1 or $10 \mu M$ ramiprilat for $24 \mathrm{~h}$. b Expression of AT1/AT2 in HUVEC after treatment with 1 or $10 \mu M$ simvastatin for $24 \mathrm{~h}$. c HUVEC were treated with different concentrations ( 1 and $10 \mu M)$ of ramiprilat over various times $(2 \mathrm{~h}, 12 \mathrm{~h}, 24 \mathrm{~h})$. AT1 expression was assayed by FACS after staining as described in the Method section. The basal expression depicted by the dashed line is set as $100 \%$. d HUVEC were treated for $24 \mathrm{~h}$ with either ramiprilat or captopril at different concentrations (100 $\mathrm{n} M, 1 \mu M$, $10 \mu M)$. Data are generated and presented as described for $\mathbf{c}$. $\mathrm{n}=3$, values are given as mean $\pm \mathrm{SD}$. * in $\mathbf{c}$ and $\mathbf{d}$ indicates significant differences compared to basal expression at $\mathrm{p}<0.01$.

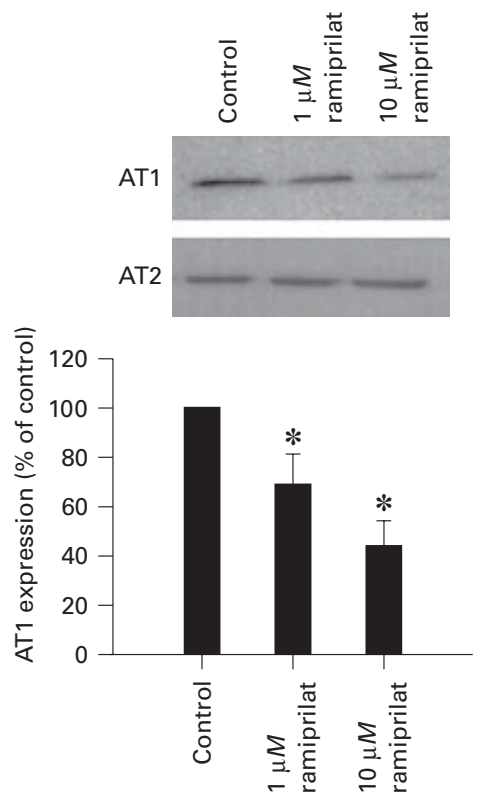

c

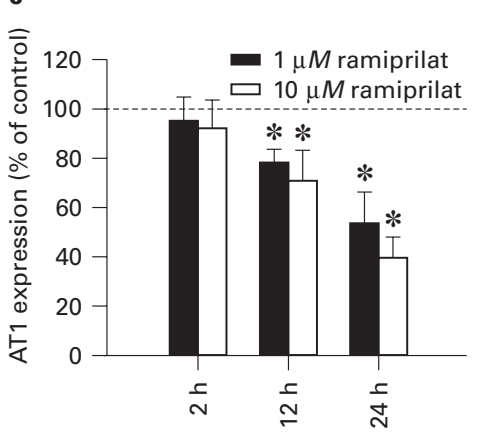

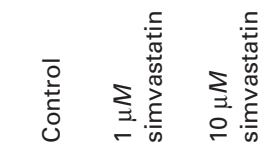
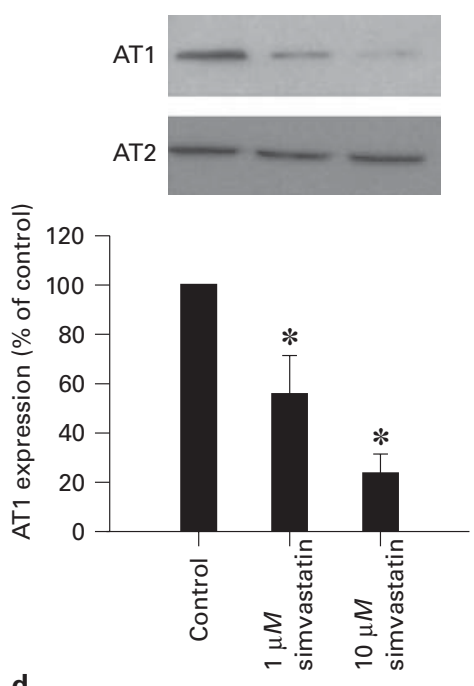

d

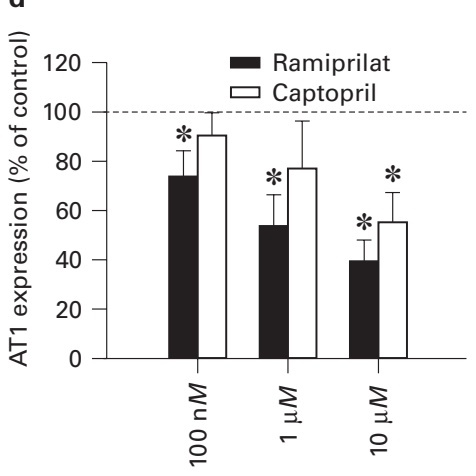

5c) and dose-dependent (fig. 5d). While treatment of HUVEC with ramiprilat over $2 \mathrm{~h}$ had no significant effect on AT1 expression, prolonged treatment over 12 or $24 \mathrm{~h}$ caused a significant reduction in AT1 levels. After a 24hour treatment as little as $100 \mathrm{n} M$ of ramiprilat reduced AT1 expression significantly. Furthermore, an acute treatment with $10 \mu M$ ramiprilat over $15 \mathrm{~min}$ and subsequent fixation, staining and analysis revealed no decreased expression of AT1 (data not shown). On the other hand, treatment with captopril, another ACE inhibitor, required higher doses to influence AT1 expression significantly. $10 \mu M$ of captopril were found to be as potent as $1 \mu M$ of ramiprilat with regard to AT1 reduction (fig. 5d).
HOE-140 Partially Reverses the Ramiprilat-Mediated AT1 Downregulation and the Ramiprilat-Dependent Reduction of ICAM-1 Expression

Among the mechanisms contributing to downregulation of AT1 by ramiprilat, elevated bradykinin levels during ACE inhibition may be involved. Therefore, we tested the effect of the bradykinin 1 receptor (B1R) antagonist des-Arg ${ }^{9},\left[\mathrm{Leu}^{8}\right]$-bradykinin and the bradykinin 2 receptor (B2R) antagonist HOE-140 in our system. Treatment with HOE-140 partially reversed downregulation of AT1 by ramiprilat, while incubation with the B1R antagonist had no substantial effect (fig. 6a). Combination of the two antagonists had no additional effect compared to HOE-140 alone. However, treatment with HOE-140 
Fig. 6. Effect of bradykinin receptor antagonists on the ramiprilat-induced downregulation of AT1 (a) and ICAM-1 expression (b). a Expression of AT1 on HUVEC was analyzed by FACS. Cells were treated with ramiprilat $(10 \mu M, 24 \mathrm{~h})$, HOE-140 $(500 \mathrm{n} M, 24 \mathrm{~h})$, des-Arg ${ }^{9},\left[\mathrm{Leu}^{8}\right]$-bradyki$\operatorname{nin}(10 \mu M, 24 \mathrm{~h})$, and the combination of both antagonists combined with ramiprilat. The figure gives the relative AT1 expression compared to untreated control which is set to $100 \% . \mathrm{n}=3$, values are given as mean \pm SD. b HUVEC were treated with AngII $(1 \mu M, 6 \mathrm{~h})$ and ramiprilat $(1 \mu M, 20 \mathrm{~h}$ prior to AngII stimulation). Where indicated, HOE-140 (500 nM) or des-Arg ${ }^{9}$, [Leu ${ }^{8}$ ]-bradykinin $(10 \mu M)$ were added together with ramiprilat. ICAM-1 expression was measured using FACS. Dashed line represents the basal expression of ICAM-1. * $\mathrm{p}<0.01$, $\mathrm{n}=4$, values are given as mean \pm SD.

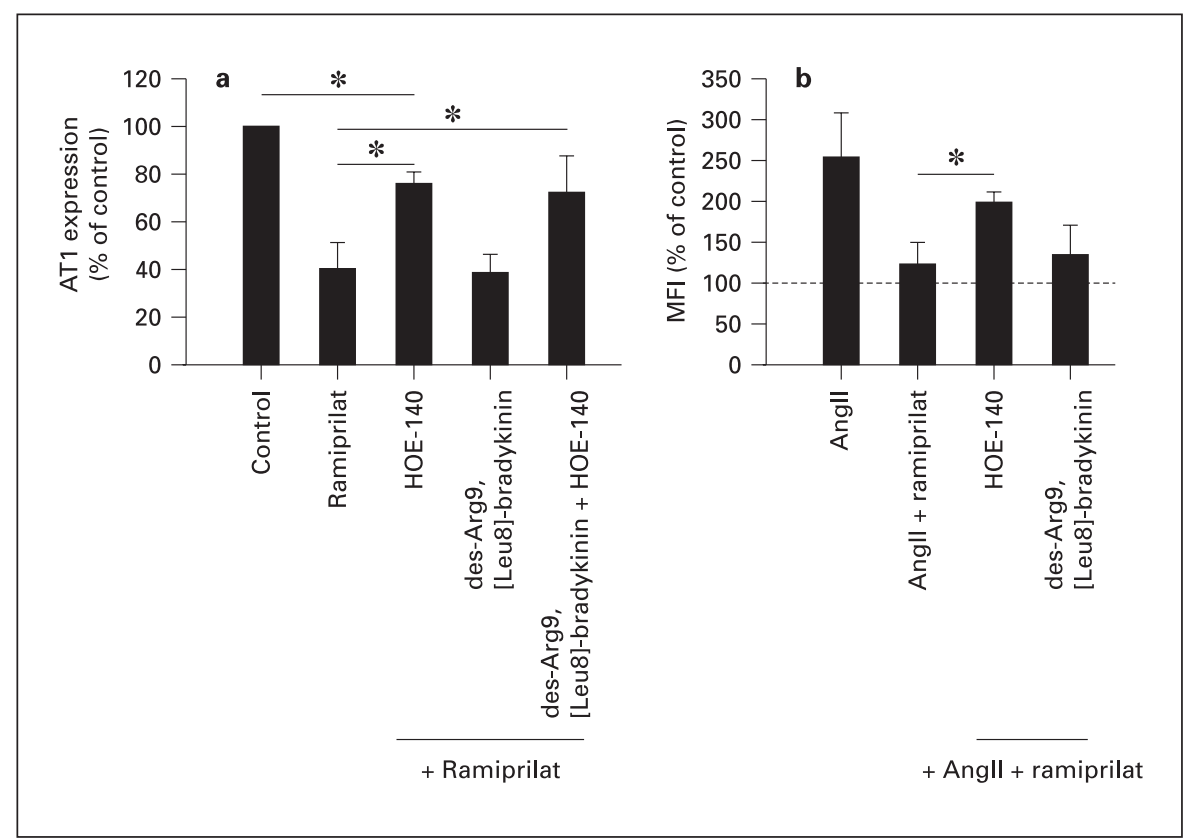

does not completely reverse the ramiprilat-mediated attenuation of AT1 expression, suggesting that other mechanisms may be involved in this process. Similarly, treatment with both HOE-140 and ramiprilat reduced the ramiprilat-mediated downregulation of adhesion molecules after AngII stimulation as shown for ICAM-1 in figure $6 \mathrm{~b}$. The B1R antagonist caused no significant effect in these experiments.

\section{Discussion}

Inflammation is an important factor contributing to the development and progression of atherosclerosis. AT1mediated effects have been shown to be involved in various inflammatory processes which may be crucial for the onset of ischemic heart diseases or stroke [3]. In this study we describe a mechanism by which ACE inhibition reduces AT1 expression in endothelial cells, leading to decreased adhesion molecule expression and inhibition of monocyte adhesion.

In accordance with previous reports [16, 17], our study demonstrates the enhanced expression of the adhesion molecules P-selectin, VCAM-1 and ICAM-1 in response to AngII in HUVEC. These molecules have been shown to play critical roles in the recruitment of monocytes to atherosclerotic lesions [18]. Functionally, the AngII-induced expression of these adhesion molecules leads to an increase of THP-1 cell adhesion, as observed under flow conditions. The effects of AngII on adhesion molecule expression and adhesion of THP-1 cells are clearly mediated by AT1. Although increased expression of E-selectin in response to AngII treatment has been demonstrated in previous studies [19] we were unable to confirm this finding in our experimental setting. However, differences in E-selectin expression between coronary macrovascular and microvascular endothelial cells in response to AngII have been reported [20]. Therefore, the observed lack of E-selectin induction might be attributed to the different type of endothelial cells used in this study.

Moreover, we report here that the ACE inhibitor ramiprilat reduces adhesion molecule expression in HUVEC and monocyte adhesion to these cells stimulated with AngII. Conclusively, the underlying mechanism must be independent of the suppression of AngII generation and rather interfere with RAS elements distal from AngII production. AngII receptor expression and transcription factor activity seemed to be major targets responsible for changes in adhesion molecule expression. We have previously shown that ramiprilat reduces the expression of AT1 on monocytes which may be involved in diminished chemokine expression during AngII stimulation [21]. Here we demonstrate decreased AT1 expression by ramiprilat while AT2 expression remains stable in endothelial cells. Blockage of bradykinin degradation during ACE inhibition might be of importance in this 
system. Bradykinin may cause secretion of superoxide radicals and prostaglandin $\mathrm{E}_{2}\left(\mathrm{PGE}_{2}\right)$ via $\mathrm{B} 2 \mathrm{R}$. $\mathrm{PGE}_{2}$-induced cAMP elevation and enhanced superoxide radical levels destabilize AT1 mRNA with subsequent downregulation of AT1 [22-24]. To explore the role of increased bradykinin levels in the reduced expression of AT1 we used antagonists to B1R and B2R. HOE-140 clearly attenuated the ramiprilat-mediated reduction of AT1 expression and the lowering of ICAM-1 expression. However, since HOE-140 does not completely reverse the effect of ramiprilat in lowering AT1 additional mechanisms may be of importance. Hence elevated levels of NO and angiotensin (1-7) might contribute to the reduction of AT1 expression. The NO donor S-nitroso-N-acetylpenicillamine has been shown to downregulate AT1 RNA in VSMC by $90 \%$ and protein by $60 \%[25,26]$. Furthermore, ACE inhibitors were found to directly bind to B1R with a subsequent release of NO from endothelial cells [27]. This mechanism, however, seems less important in our system, since the B1R antagonist had no effect. Angioten$\sin (1-7)$, a degradation product of angiotensin I, has also been shown to downregulate AT1 expression [28]. Further work is required to elucidate the contribution of each mechanism to the decreased AT1 expression on monocytes and endothelial cells.

As an additional mechanism for decreased adhesion molecule expression we investigated the influence of ramiprilat on NF- $\mathrm{KB}$ activity expressed as $\mathrm{p} 65$ translocation into the nucleus. In vivo and in vitro studies have shown the inhibition of the redox-sensitive transcription factor NF- $\mathrm{KB}$ by ACE inhibitors. AngII is known to enhance NF- $\kappa \mathrm{B}$ activity in various cell types, among them monocytes [29] and endothelial cells [17, 30]. As ICAM-1, VCAM-1 and P-selectin have an NF- $\mathrm{BB}$ binding site in their promoter, the enhanced expression we observed might, at least in part, be due to NF-кB activation. The mechanism by which ACE inhibitors reduce NF- $\mathrm{BB}$ activation is not known. Although most studies having dealt with this issue proclaim reduced AngII formation as main mechanism, this does not seem to be the case in our investigation. A recent study, however, reported the involvement of peroxisome proliferator-activated receptor (PPAR) $\alpha$ in an in vivo model of Ang-II-induced inflammation [31]. In this study, enalapril reduced the AngII-mediated chemokine and adhesion molecule expression in mice aortas. PPAR- $\alpha$ and $-\gamma$ were simultaneously increased after ACE inhibitor treatment. PPARs are known to inhibit NF- $\mathrm{KB}$ activation by interfering with ІкВ $[32,33]$. However, a plausible mechanism for the reduced p65 translocation in this study is the reduction of
AT1 expression, which may be responsible for reduced signalling events after AngII treatment. The fact that the LPS-induced CAM expression is attenuated by ramiprilat, points to the possibility that there may be AT1-independent mechanisms involved. In addition, recent publications indicate that NF- $\mathrm{KB}$ is also activated after binding of AngII to AT2. However, this seems unlikely in our system, since the p65 translocation is blocked by losartan but not by PD123.319.

Accumulation of monocytes in the subendothelial space of the vessel wall is one of the earliest responses in the development of atherosclerotic lesions. Upregulation of CAMs and chemoattractants are key events for monocyte recruitment, both of which are known to be enhanced through local AngII formation. Downregulation of chemoattractant production [21] and reduced adhesion molecule expression, as found in this study and by da Cunha et al. [31], by ACE inhibitors despite AngII generation may offer an explanation for the anti-atherogenic and anti-inflammatory properties of these drugs.

\section{Acknowledgements}

This work was supported by the Interdisciplinary Center for Clinical Research (IZKF, Project No B29) of the University of Erlangen-Nuremberg, the Swedish Research Council, the Swedish Heart-Lung Foundation, and the AFA Health Fund. The authors would like to thank Heike Kloos, Sabine Kesting, and Doris Flick (all Medical Clinic II, University of Erlangen, Germany) for excellent technical assistance and Ellinor Kenne (Department of Physiology and Pharmacology, Karolinska Institutet, Stockholm, Sweden) for help with statistical analysis and proofreading. 


\section{References}

1 Libby P: Changing concepts of atherogenesis. J Intern Med 2000;47:349-358.

2 Ross R: Atherosclerosis - an inflammatory disease. N Engl J Med 1999;340:115-126.

3 Brasier AR, Recinos A 3rd, Eledrisi MS: Vascular inflammation and the renin-angiotensin system. Arterioscler Thromb Vasc Biol 2002; 22:1257-1266.

4 Wagenaar LJ, Vorrs AA, Buiema H, van Gilst WH: Angiotensin receptors in the cardiovascular system. Can J Cardiol 2002;18:13311339.

5 Collins T, Cybulsky MI: NF-кB: pivotal mediator or innocent bystander in atherogenesis? J Clin Invest 2001;107:255-264.

6 Phillips MI, Kagiyama S: Angiotensin II as a pro-inflammatory mediator. Curr Opin Investig Drugs 2002;3:569-577.

7 Dzau VJ: Circulating versus local renin-angiotensin system in cardiovascular homeostasis. Circulation 1988;77(6 pt 2):14-13.

8 Arakawa K, Urata $\mathrm{H}$ : Hypothesis regarding the pathophysiological role of alternative pathways of angiotensin II formation in atherosclerosis. Hypertension 2000;36:638-641.

9 Kinoshita A, Urata H, Bumpus FM, Husain A: Multiple determinants for the high substrate specificity of an angiotensin II-forming chymase from the human heart. J Biol Chem 1991; 266:19192-19197.

10 Snyder RA, Kaempfer CE, Wintroub BU: Chemistry of a human monocyte-derived cell line (U937): Identification of the angiotensin I-converting activity as leukocyte cathepsin G. Blood 1985;65:176-182.

11 Berkenboom G, Langer I, Carpentier Y, Grosfils K, Fontaine J: Ramipril prevents endothelial dysfunction induced by oxidized low-density lipoproteins: A bradykinin-dependent mechanism. Hypertension 1997;30:371-376.

12 Sun YP, Zhu BQ, Browne AE, Pulukurthy S, Chou TM, Sudhir K, Glantz SA, Deedwania PC, Chatterjee K, Parmley WW: Comparative effects of ACE inhibitors and an angiotensin receptor blocker on atherosclerosis and vascular function. J Cardiovasc Pharmacol Ther 2001;6:175-181.

13 Soehnlein O, Xie X, Ulbrich H, Kenne E, Rotzius P, Flodgaard H, Eriksson EE, Lindbom L: Neutrophil-derived HBP (CAP37) deposited on endothelium enhances monocyte arrest under flow conditions. J Immunol 2005; 174:6399-6405.
14 Blaecke A, Delneste Y, Herbault N, Jeannin P, Bonnefoy JY, Beck A, Aubry JP: Measurement of nuclear factor-kappa B translocation on lipopolysaccharide-activated human dendritic cells by confocal microscopy and flow cytometry. Cytometry 2002; 48:71-79.

15 Ichiki $\mathrm{T}$, Takeda $\mathrm{K}$, Tokunou $\mathrm{T}$, Iino $\mathrm{N}$, Egashira K, Shimokawa H, Hirano K, Kanaide H, Takeshita A: Downregulation of angiotensin II type 1 receptor by hydrophobic 3-hydroxy-3-methylglutaryl coenzyme A reductase inhibitors in vascular smooth muscle cells. Arterioscler Thromb Vasc Biol 2001;21:18961901.

16 Tayeh MA, Scicli AG: Angiotensin II and bradykinin regulate the expression of $\mathrm{P}$-selectin on the surface of endothelial cells in culture. Proc Assoc Am Physicians 1998;110:412-421.

17 Pueyo ME, Gonzelez W, Nicoletti A, Savoie F, Amal JF, Michel JB: Angiotensin II stimulates endothelial vascular cell adhesion molecule-1 via nuclear factor-kappaB activation induced by intracellular oxidative stress. Arterioscler Thromb Vasc Biol 2000;20:645-651.

18 Huo Y, Ley K: Adhesion molecules and atherogenesis. Acta Physiol Scand 2001;173:3543.

19 Grafe M, Auch-Schwelk W, Zakrzewicz A, Regitz-Zagrosek V, Bartsch P, Graf K, Loebe M, Gaehtgens P, Fleck E: Angiotensin II-induced leukocyte adhesion on human coronary endothelial cells is mediated by E-selectin. Circ Res 1997;81:804-811.

20 Grafe M, Zakrzewicz A, Graf K, Gaehtgens P, Fleck E: Differential reaction of human cardiac macro- and microvascular endothelial cells with respect to leucocyte adhesion and exposition to atherogenic lipoproteins. Z Kardiol 1999;88:828-837.

21 Schmeisser A, Soehnlein O, Illmer T, Lorenz HM, Eskafi S, Roerick O, Gabler C, Strasser R, Daniel WG, Garlichs CD: ACE inhibition lowers angiotensin II-induced chemokine expression by reduction of NF-kappaB activity and AT1 receptor expression. Biochem Biophys Res Commun 2004;325:532-540.

22 Wang X, Nickenig G, Murphy TJ: The vascular smooth muscle type I angiotensin II receptor mRNA is destabilized by cyclic AMP-elevating agents. Mol Pharmacol 1997;52: 781-787.

23 Nickenig G, Strehlow K, Baumer AT, Baudler S, Mann S, Sauer H, Bohm M: Negative feedback regulation of reactive oxygen species on AT1 receptor gene expression. Br J Pharmacol 2000;131:795-803.
24 Raddassi K, Petit JF, Lemaire G: LPS-induced activation of primed murine peritoneal macrophages is modulated by prostaglandins and cyclic nucleotides. Cell Immunol 1993;149:5064.

25 Ichiki T, Usui M, Kato M, Funakoshi Y, Ito K, Egashira K, Takeshita A: Downregulation of angiotensin II type 1 receptor gene transcription by nitric oxide. Hypertension 1998;31(1 pt 2):342-348.

26 Cahill PA, Redmond EM, Foster C, Sitzmann JV: Nitric oxide regulates angiotensin II receptors in vascular smooth muscle cells. Eur J Pharmacol 1995;288:219-229.

27 Ignjatovic T, Tan F, Brovkovych V, Skidgel RA, Erdos EG: Novel mode of action of angiotensin I converting enzyme inhibitors: direct activation of bradykinin B1 receptor. J Biol Chem 2002;277:16847-16852.

28 Clark MA, Tallant EA, Tommasi E, Bosch S, Diz DI: Angiotensin-(1-7) reduces renal angiotensin II receptors through a cyclooxygenasedependent mechanism. J Cardiovasc Pharmacol. 2003;41:276-83.

29 Kranzhofer R, Browatzki M, Schmidt J, Kubler $\mathrm{W}$ : Angiotensin II activates the proinflammatory transcription factor nuclear factor-kappaB in human monocytes. Biochem Biophys Res Commun. 1999;257:826-828.

30 Costanzo A, Moretti F, Bugio VL, Bravi C, Guido F, Levriero M, Puri PL: Endothelial activation by angiotensin II through NFkappaB and p38 pathways: Involvement of NFkappaBinducible kinase (NIK), free oxygen radicals, and selective inhibition by aspirin. $\mathrm{J}$ Cell Physiol 2003;195:402-410.

31 da Cunha V, Tham DM, Martin-McNulty B, Deng G, Ho JJ, Wilson DW, Rutledge JC, Vergona R, Sullivan ME, Wang YX: Enalapril attenuates angiotensin II-induced atherosclerosis and vascular inflammation. Atherosclerosis 2005; 178:9-17.

32 Delerive P, Gervois P, Fruchart JC, Staels B: Induction of IkappaBalpha expression as a mechanism contributing to the anti-inflammatory activities of peroxisome proliferator-activated receptor-alpha activators. J Biol Chem 2000;275:36703-36707.

33 Delerive P, De Bosscher K, Besnard S, Vanden Berghe W, Peters JM, Gonzalez FJ, Fruchart JC, Tedgui A, Haegeman G, Staels B: Peroxisome proliferator-activated receptor alpha negatively regulates the vascular inflammatory gene response by negative cross-talk with transcription factors NF-kappaB and AP-1. J Biol Chem 1999;274:32048-32054. 